\title{
Sobre Homens, Botos e Peixes: dimensões poético-imaginárias de uma Ecoantropologia Urbana de coletivos humanimais no sul do Brasil
}

Flávio Leonel Abreu da Silveira ${ }^{a}$

A proposta do artigo é a de discutir as dimensões sensíveis e cosmopolíticas da pesca cooperativa entre botos-da-barra e pescadores artesanais de tarrafa no contexto do estuário do Rio Tramandaí (RS), a partir de uma abordagem dialógica entre Antropologia e outras disciplinas, a fim de propor uma perspectiva de estudos sobre a cidade que chamo de Ecoantropologia Urbana.

Botos, Pescadores, Estuário, Cidade, Ecoantropologia urbana.

A proposta deste artigo $^{1}$ é realizar uma experimentação textual a partir de experiência etnográfica ${ }^{2}$ junto aos pescadores da barra do rio Tramandaí, que realizam a chamada 'pesca cooperativa' em associação com os botos-da-barra (Tursiops gephyreus ${ }^{3}$ ), cetáceos marinhos que adentram o estuário movidos pela intenção de capturarem/predarem peixes que ocorrem naquele ambiente de encontro de águas em meio urbano. A etnografia que realizei ocorreu entre o segundo semestre de 2018 e o primeiro de 2019, quando busquei conviver no ambiente da barra com os pescadores e acompanhar as suas atividades de pesca junto aos golfinhos. Também acompanhei atividades dos pesquisadores

a Professor Associado da Universidade Federal do Pará, Docente do Programa de Pós-Graduação em Sociologia e Antropologia-PPGSA (UFPA). Email: flabreu@ ufpa.br. 
ligados ao CECLIMAR - Centro de Estudos Costeiros, Limnológicos e Marinhos - ligados ao Campus Litoral Norte da Universidade Federal do Rio Grande do Sul, mais diretamente de alguns trabalhos de campo realizados pelos membros do Projeto Botos da Barra.

Trata-se do empenho de produzir uma narrativa poético-etnográfica que considere às dimensões imaginárias, porque simbólico-práticas, das 'formas sensíveis' de socialidades interespécies que convivem no estuário do rio Tramandaí, que considere, tensionalmente, ontologias em relação num locus comum de entrelaçamentos de mundos. Elas engendram expressões cosmopolíticas ${ }^{4}$ de relações entre diferenças coligadas, neste caso, imersas num contexto tensional de expansão do capitalismo expropriador dos lugares de pertença coexistencial de existentes - humanos, botos, tainhas, e muitos outros - naquele meio/ ambiência, quando o caráter convivial das ontologias entrelaçadas numa 'ecologia das práticas' (aqui entendida como um conjunto de experiências compartilhadas (e interessadas) por coletivos que praticam os lugares ${ }^{5}$ ) precisa lidar com as ações fragmentadoras da unicidade em jogo - como ficará mais claro adiante - onde o comum enquanto dimensão da vida vivida em assembleias de existentes é transfigurado no (in)comum do desejo consumista do fruir nas paisagens de evasão, pelo olhar fotográfico insaciável (Urry 1992) que tudo registra.

Há, portanto, uma tensão entre a cosmopolíticas que entrelaça ontologias distintas no pluridiverso das formas biossociais e culturais em devir nas paisagens, com o cosmopolitismo que busca pela via da turistificação dos espaços, o olhar estrangeiro e as sociações mais ou menos informais movidas pela circulação do dinheiro (Simmel 1971), o que sugere outras cosmopolíticas possíveis (Blaser 2018) que opõe empresários/empreiteiros e pescadores artesanais quanto às formas de interações com os coletivos Tursiops. Ou ainda, seria o caso de pensarmos numa biocenose que inclui o humano porque a natureculture (Fuentes 2010) flui nas ações (intra, inter, transespécies), na fulguração de uma espécie de Cosmoceno em choque com a expansão do Capitaloceno ${ }^{7}$, que se volta ao uso das paisagens compreendidas 
como recursos, apartando o humano da natureza no anseio mesmo de possuí-la como produto.

Há uma lógica de mercado voltada ao aumento do turismo na região que está ligada a certo economicismo devastador capaz de motivar extinções no contemporâneo, e que se assenta agressivamente sobre os ecossistemas costeiros vinculados aos biomas Mata Atlântica e Pampa na porção sul-riograndense. Com isso não quero dizer que os pescadores artesanais não joguem o social (ou não precisem dele), no sentido de participarem das dinâmicas que contribuem à circulação do dinheiro (jogos esses que também são ativados por elas), com o intuito de se manterem ativos na pesca cooperativa no contexto do Tramandaí. O que ressalto é justo a coexistência sensível de uma cosmopolítica de interações entre humanos e cetáceos experienciada na artesania do ofício que gira em torno das errâncias agentivas dos cardumes de peixes no estuário - o que implica manterem-se íntegras as interagências nos lugares praticados pelos coletivos, neste caso, como seres sencientes multidiversos no mundo austral brasileiro, diante das pressões sobre o vivo e à pertença à localidade dos espaços estuarinos, agindo como degradadora de uma memória de relações onto-ecológicas de reconhecida duração na barra.

$\mathrm{O}$ fenômeno biosocial da pesca cooperativa entre humanos e cetáceos marinhos (botos-de-lahille - Tursiops gephyreus) que ocorre na área denominada de barra do rio Tramandaí - ou simplesmente na barra - situada no litoral norte do Rio Grande do Sul, revela formas complexas e sensíveis de interações/associações entre coletivos humanimais em contexto de adensamento urbano. Neste caso, entre dois mamíferos (humanos e golfinhos) que praticam conjuntamente a captura de determinados peixes - neste caso, duas espécies de tainhas (Mugil sp.), ainda que capturem outros peixes - tornando-os frequentadores assíduos de um pequeno trecho do Tramandaí que encontra o oceano Atlântico, localizado entre duas cidades litorâneas gaúchas com significativa vocação turística - Tramandaí e Imbé - e, devido a isso, suscetíveis à intensa especulação imobiliária. 
Os botos da barra, como são conhecidos os cetáceos, praticam o lugar junto aos coletivos de pescadores artesanais há bastante tempo - estima-se que a pesca cooperativa ocorra há pelo menos 60 anos no local - e, como os humanos, são habitués da zona estuarina onde mantêm uma longa tradição ${ }^{8}$ de pesca consorciada com os pescadores artesanais, especialmente àqueles que se utilizam de tarrafas em seu ofício. A pesca cooperativa pode ser observada durante o ano todo, mas se intensifica no período de migração das tainhas no Atlântico durante o inverno austral. A porção litorânea que corresponde ao sul do Brasil é considerada uma área de altíssima biodiversidade - nela convergem a corrente quente (do Brasil) que encontra a corrente fria das Malvinas, produzindo condições adequadas para a manutenção de cadeias tróficas bastante complexas naquela zona de contato.

Os encontros e as vinculações sistêmicas, de comunicação ritualizada e agentiva entre humanos e coletivos Tursiops são movidos por um querer estar-juntos altamente sensível, envolvendo reciprocidades e intencionalidades entre ambos na captura das tainhas, constituindo formas simbólico-práticas singulares que entrelaçam jogo e labuta no ofício de pescar cooperativamente, quando captura e fuga entendidas como configurações elaboradas de socialidades interespécies, oscilam/tensionam díades cooperativas e triangulações agonísticas, que retomarei mais adiante.

A pesca cooperativa entre humanos e golfinhos é um fenômeno raro. Há registros de que ela aparece em determinados pontos do mundo relacionando diferentes coletivos de cetáceos (aqui me refiro a espécies) a coletivos humanos distintos. No caso da África (Mauritânia), Oceania (Austrália) e Ásia (Mianmar) envolve tipos de pescas que podem ser consideradas como cooperativas. Existem, no entanto, referências (nem sempre comprovadas) a relações de proximidades amistosas e lúdicas ${ }^{9}$, ou mesmo, tensionais entre humanos e cetáceos em diversas regiões do país (e das Américas), bem como nos demais continentes.

O sapiens interage desde longa data com cetáceos marinhos e dulciaquícolas. Há relatos desde Plínio, o Velho, de eventos 
denominados hodiernamente como sendo 'pesca cooperativa' (Busnel 1973; Simões-Lopes 2005). Sabe-se, no entanto, que esta prática de associação humanimal - enquanto fenômeno complexo e expressão formal de sociações interespécies - é bem conhecida pelos biólogos que atuam no litoral sul do Brasil, e que somente agora tem despertado interesse dos antropólogos, como é o caso dos estudos de Iino (2017) e Catão (2019) para o contexto de Laguna (SC), e o de Marques (2017) para Tramandai/Imbé (RS), cujas pesquisas etnográficas consideram as interações entre botos e os pescadores artesanais.

Entretanto, para o contexto gaúcho, pelo menos desde o debate proposto por Tabajara (1992) em seu estudo pioneiro, é conhecida a fidelidade de coletivos Tursiops ao estuário do Tramandaí, remetendo a associação à segunda metade do século XX. O autor cita, por exemplo, o golfinho nomeado de Galhamol pelos pescadores locais, que à época frequentava as águas da barra há 37 anos. Atualmente, Geraldona, a matriarca do grupo (11 indivíduos residentes e 6 que tentam entrar naquele ambiente) que cotidianamente deambula pela barra, possui aproximadamente 37 anos, sendo que vários de seus filhotes foram criados junto ao estuário. Além disso, a presença de indivíduos mais ou menos errantes no local é verificada, mas observações recentes parecem indicar que a fidelidade à barra implica a proteção do território familiar, já que Chiquinho (com cerca de 12 anos) foi identificado impedindo a entrada de Tursiops estranhos no estuário ${ }^{10}$. Há uma série de estudos que indicam a fidelidade/territorialidade em relação ao Tramandaí como uma prática desses cetáceos (Simões-Lopes 2005; Simões-Lopes \& Daura-Jorge 2008), bem como a significativa quantidade de dados que os pesquisadores do Projeto Botos da Barra acumularam nos longos anos de pesquisas na área, parte publicada em artigos científicos, trabalhos de graduação e pós-graduação, bem como publicações de cunho educativo (Educação Ambiental) dentro da proposta de trabalhos de extensão que o grupo executa.

Mais recentemente, Giacomo \& Ott (2016) ao discutirem a alta fidelidade dos botos ao estuário do rio Tramandaí indicaram, a partir da 
análise de imagens obtidas pelo registro fotográfico/fotoidentificação das nadadeiras dorsais, que a presença de alguns indivíduos da espécie no local (pelo menos quatro deles), dura 18 anos. Eles são, portanto, considerados residentes naquela zona estuarina, realizando movimentações cotidianas entre o oceano e o rio Tramandaí (ligado diretamente ao complexo lagunar Tramandaí-Armazém).

A partir da pesquisa de Ilha (2016), mas também através dos meus dados de campo, fica claro que as pessoas pescam cooperativamente com os botos há bastante tempo, pois é comum escutar de alguns pescadores que a atividade ocorre há décadas, podendo variar entre 30, 40 ou 50 anos, dependendo do pescador e de como cada um recorda as suas atividades conjuntas com os animais ${ }^{11}$, sendo que muitos deles aprenderam a pescar em parceria com os botos a partir dos ensinamentos obtidos dos mais velhos (parentes e amigos) que conviviam com os cetáceos e tinham como prática cotidiana a pesca interspécies desde longa data.

Os eventos cotidianos de pesca botos-homens no contexto urbano enquanto experiências comunicacionais complexas, estabelecem laços duradouros pautados em vínculos simbólico-práticos e afetivos que envolvem formas intersubjetivas de amizades interespécies, cuja intencionalidade é a predação das tainhas que se aproximam da costa - para se desenvolverem, descansarem, em busca de alimentação, ou seja, para utilizarem o estuário nos seus ciclos vitais. As tainhas no contexto da pesca cooperativa representam um vetor de relações ${ }^{12}$ que entrelaça os coletivos de mamíferos sociais. Tais laços, por certo, precisam ser melhor compreendidos através do aprofundamento da pesquisa etnográfica, mas o material de que disponho a partir do trabalho de campo, juntamente com o vasto material acumulado pelo grupo de pesquisa Botos da Barra, permite por ora uma série de reflexões.

Neste sentido, as complexidades presentes no fenômeno da pesca colaborativa interespécies, levadas a efeito mediante formas táticas e sensíveis dejogar associativamente o evento 'pesca', éentendido por mim 
como um esforço comunicacional entre inteligências humanimais ${ }^{13}$ : envolvendo significações, pontos de vista, intencionalidades, gestos, movimentos, sinalizações e vocalizações em torno dos acontecimentos de predação e fuga - produzindo uma triangulação complexa e dinâmica de sociações prazerosas, competitivas, colaborativas, mais ou menos agonísticas.

Nos termos de Bateson (2000) e de Ingold (2000) implicam certas habilidades no engajamento de captura coletiva dos cardumes que também desenvolverão habilidades quanto ao escape. As fêmeas de boto (as 'botas') que adentram o estuário com os filhotes precisam ensiná-los a desenvolver a atenção ${ }^{14}$ às formas de pesca cooperativa, da mesma maneira que os pescadores precisam ensinar na prática os neófitos a pescarem conjuntamente. As sinalizações com o rostro ('mostrá com a cabecinha' e /ou 'com o biquinho') e 'com a cola' [o mesmo que cauda] devem ser estimuladas, já que o jovem cetáceo aprende experienciando/experimentando a pescaria ${ }^{15}$ - observando a mãe e estimulado por ela - da mesma forma que o pescador deve observar suas investidas e estimulá-lo, mesmo que ele 'esteja mentindo', que seja 'louquinho' e afobado na pesca e/ou quanto ao processo de indução do pescador ao lançamento da tarrafa, sendo necessário sempre evitar que ele se prenda às malhas do artefato.

A entrada intencional dos botos na barra e o início da pesca (que é cooperativa entre os cetáceos) desencadeia a chamada 'corrida de boto' entre os humanos, que implica correr acompanhando a movimentação dos cetáceos na condução do cardume até as margens/ barrancos da barra, a fim de lançarem as tarrafas sobre os peixes, pois os pescadores competem entre si por uma posição mais adequada ao lançamento da rede ${ }^{16}$. Há uma hermenêutica sensível do derivar das paisagens aquáticas que indica tanto as posições das tainhas quanto a dos golfinhos: vibrações, ondulações, sombras, bolhas, respiros/ borrifos são signos fundamentais, que os pescadores interpretam com astúcia e acuidade quando perscrutam sensivelmente a ambiência local. Além do mais é corrente entre eles a informação de que os 
botos habitués da barra os reconhecem, assim como os pescadores os identificam pelo seu 'jeitão' ${ }^{17}$, dando-lhes nomes próprios (Lobisomem, Chiquinho, Coquinho, Geraldona, Rubinha, entre outros).

As tainhas, por sua vez, participam do jogo social agonístico 'pesca cooperativa' como alvos, pois são vetores de relação que mobilizam uma triangulação de agentes e precisam realizar a fuga diante dos atos de predação - o cardume movimenta-se como uma espécie de macroorganismo híper-sensivel e senciente que interpreta as interagências botos-humanos e busca evitá-las como pode a partir de deslizamentos, de escapes táticos diante de dois predadores que trabalham estrategicemente juntos. Na realidade, as tainhas instituem o fenômeno lupasciano (1947) do terceiro incluído. Os cetáceos, não precisam dos humanos para capturarem as tainhas, da mesma forma que os pescadores não necessitam dos botos para pescarem, todavia, sabem que o manejo cetáceo, uma espécie de arrebanhamento das tainhas do meio do canal para as margens é fundamental à captura dos peixes ${ }^{18}$.

Acontece que as tainhas vinculam ecossistêmica e simbolicamente humanos e botos. Elas instauram processualmente pela sua presença agentiva no estuário a convergência simbólico-prática de estratégias de captura. A relação boto-tainha inclui um terceiro que é o humano, da mesma forma em que a relação tainha-humano inclui os cetáceos. Mas as tainhas utilizam táticas de escape: inteligentemente, elas enquanto cardumes driblam as agências mamíferas interespécies. É justo pela pressão dos cetáceos em relação ao lançamento da tarrafa que elas se dispersam e são predadas por ambos. Os botos utilizam-se das ferramentas humanas, operando indiretamente o artefato na captura das presas, assim como os humanos sabem se utilizar das técnicas corporais dos cetáceos para o exercício criativo da pesca.

Portanto, as associações e dissociações presentes nos comportamentos de fuga-captura vinculados à pesca cooperativa são altamente ritualísticas, e se desenrolam nos quadros (frame) do jogo (play). Aqui tanto uma abordagem batesonia (2000) quanto elisiana 
(1992), ou mesmo, de Huizinga (1996) e de Caillois (2014), podem contribuir para o entendimento do fenômeno multiespécies que entrelaça o lúdico e a labuta - que parece ser, pelo menos para os dois mamíferos, uma experiência coletiva interespécies ritualisticamente excitante, por assim dizer, pela sua dimensão simbólica e de aventura prazerosa, até certo ponto vertiginosa, já que ecossistemicamente a pesca cooperativa se distende para além da triangulação botos-tainhashumanos e seus jogos humanimais no enquadre que a barra representa em termos socioambientais, naquele contexto de interações ${ }^{19}$.

Mas, o jogo social enquanto processo de sociação interespécies, no caso da pesca cooperativa, é bastante complexo. Sabe-se com Huizinga (1996) que o jogo, para que seja entendido como experiência partilhada precisa estar constituído por regras seguidas pelos participantes, caso isso não ocorra, transforma-se em trapaça. Portanto, os mamíferos participantes produzem um diálogo técnicocultural de manejo dos peixes - que, não menos inteligentemente precisam lidar com isso, ou ainda, aprenderem a evitar as estratégias cooperativas de captura quando adentram o estuário - e que se traduz em um conjunto de práticas herdadas, negociadas, transformadas intergeracionalmente por humanos e botos na barra do Tramandaí através daquela prática convivial.

Nem sempre o jogo segue regras estritas na pesca cooperativa, pois tanto golfinhos podem roubar peixes já contidos na tarrafa mergulhando por debaixo dela e capturando-os - como pescadores podem tarrafear e tirar a tainha 'do bico do boto', irritando, inclusive, os cetáceos. Enfim, cooperam entre si, mas roubam também uns dos outros quando possível - o que se desdobra, ainda, na disputa humana por espaços para o lançamento da tarrafa. Ora, tal dinâmica de jogotrapaça não provoca inimizades entre os participantes, mas instaura, seguindo Bateson (2000), formas padronizadas de cismogêneses complementares (formas de cooperação/atitudes relacionais diferentes mas apropriadas ao jogo, como é o caso de ceder peixes ao outro no ato da pesca) e simétricas (competição/exibição da mesma 
resposta relacional - adiantar-se na captura; roubar). Tais processos cismogênicos desdobram-se em imagens morais do boto: 'botinho' bom (que trabalha) e do boto mau 'preguiçoso', 'ladrão'. Tais expressões são comuns em Laguna (SC), mas nem tanto no Tramandaí, pois quando aparecem têm relação com aqueles pescadores que transitam pelo litoral catarinense quando em visita a conhecidos ou parentes, uma vez que há contato mais ou menos frequente entre os dois contextos de pesca cooperativa no sul do país.

As reflexões sobre a pesca cooperativa colocam ao antropólogo o desafio de refletir sobre os dilemas em torno do continuum tensional e criativo, por certo, do fazer etnográfico-pensar antropológico ${ }^{20}$, associado à abertura epistemo-ontológica ${ }^{21}$ que tanto diz respeito ao diálogo interdisciplinar (Durand 1993; Velho 2011) com outros campos do saber. Entendo que o caráter intersticial e micro da Antropologia ${ }^{22}$ permite entendê-la com uma espécie de conector entre os campos, repleto de ruídos e elipses na produção de novas ordens de entendimento dos fenômenos, porque capaz de aproximá-los nas diferenças, já que se entranha sutilmente nos saberes. Há, ainda, a necessária sensibilidade ético-estética no cercamento do tema, que se traduz em algumas dimensões sobre os fatos sociais complexos, que me parecem conexas: 1) mediante uma ecosofia ${ }^{23}$ que procura a aderência às imagens evocadas pelos cetáceos ${ }^{24}$ em relação com outros coletivos naquele contexto; 2) a simbólica das imagens dos cetáceos que reivindica uma atenção às funções tanto do real quanto do irreal entrelaçadas ao lugar - porque jamais separadas no plano de uma imaginería ${ }^{25}$, e aí tocando certo plano das hermenêuticas sensíveis e potências arquetipais (remetendo a como as imagens dos golfinhos vibram no inconsciente humano e se atualizam naquele contexto urbano); 3) mas que acima de tudo requer uma mesma aderência às expressões formais e imagéticas manifestas pelos mundos-próprios dos cetáceos, como se apresentam em termos eto-ontológicos, não menos passíveis de leituras sutis pelos nativos, como pelo antropólogo em campo - quando não, da equipe de biólogos na qual o etnógrafo se insere na barra. 
Nestes termos, trata-se de recuperar o lugar de agência animal no corpo do socius como sugere Baratay (2010), vislumbrados como entes cuja senciência e proximidade seriam relevantes para e na existência humana, como copartícipes do mundo social e figuras implicadas em experiências ontológicas/culturais/civilizacionais diversas que fazem o mundo conosco, ainda que mantenham sua autonomia em relação a nós, e que realizem leituras próprias acerca do que significamos como ameaça ou possível associação aos seus mundos. Enfim, como produtores conosco de relações simbólicopráticas em diferentes contextos envolvendo domesticações ou não, na medida em que participam com os humanos de tais redes de significações, e não figuram apenas como coadjuvantes. Somos as paisagens com eles e os demais existentes num devir processual e implicado ${ }^{26}$.

A partir daí penso o dinamismo simbólico e ecossistêmico que se processa na ecologia do estuário como uma devir paisageiro (Sansot 1983; Eckert 2009), constituído por diversos pontos de vista (humanos e não humanos, bem como suas interagências no contexto urbano). Há uma profusão de ecologias que politicamente instauram uma fluidez tensional entre processos mentais e biosociais em jogo no estuário, articulando ambiências e socialidades que se imbricam numa natureculture, que para mim seria o mesmo que dizer num devir paisageiro.

A ideia de paisagem como devir me leva a pensá-la pelo intermédio do dinamismo das imagens encarnadas ou não nas coisas: 1) como imago ou força subjacente, e aí reveladora de amálgamas de conteúdos heteróclitos mas conexos, convergentes e desdobradas em formas multidiversas; 2) simbólicas e, por isso, re-apresentadas como epifanias $^{27}$ sensíveis nas figurações dos elementos que constiuem o estuário como paisagens em processo; 3) ora pela não-linearidade, ora pela intencionalidade nas formas em processo no espaço-tempo; 4) tanto como fulguração quanto constelação de imagens, como coprodução mestiça de existentes em relação. 
Simmel (1977), demonstrou como a ruína resulta de um jogo de forças conflitivo, movido por agências distintas que implicam o entrelaçamento/emaranhamento da natureza e da cultura consubstanciadas numa paisagem derruída, ruiniforme, que poderíamos chamar com Omar Calabrese (1989) de uma 'forma informe' em processo transformacional, daí que a ruína seria também uma espécie de 'terceiro incluído' (Lupasco 1947) entre ambas. Ela confunde o que seria natureza com a cultura e viceversa. Produzindo diferenças redefine o construto humano, dinamiza novas ontologias. Certos 'hibridismos' como alguns sugerem emergiriam ali. O devir em Simmel e suas reflexões sobre a paisagem, a ponte e a porta, por exemplo, encontram ressonâncias na visão de paisagem como forma em devir, sempre plural, como aparece em Lezama Lima (1981, 1988).

Assim, interessa-me a perspectiva de toma-la como uma expressão formal pela proximidade do pensamento/ensaismo simmeliano à poética lezamiana. Nestes termos, opero com a ideia de paisagem como devir porque a compreendo como processo coexistencial multidiverso - de seres, significações, de coisas - em contínua tensão entre mudança e permanência/proximidade e distância, portanto, sistêmica, envolvendo pontos de vista, detentora de dimensões formais, de uma poiesis.

As paisagens, como as entendo não se resumem ao ecossistêmico, nem se destacam na representação, mas vibram na sua coexistência criativa, imbricada. Se elas constituem auras é porque se entranharam como memórias nos lugares: é preciso extrair da noção de paisagem a força imagética presente na ideia de sinergia (os ciclos e as interpenetrações das matérias, as teias de relações, o fluxo de energias, as auras, os espíritos, as representações, as inteligências, as epifanias, o mysterium) na sua configuração. Existiria nelas algo como um desdobrarse não-linear no acontecer do tempo e seus entrelaçamentos nos lugares. Aqui, a questão ritmanalítica, da elasticidade das memórias que reconhece uma matriz bachelardiana e alcança a etnografia da duração 
(Rocha \& Eckert 2005), vibrando como memórias socioambientais em fluxo, parece-me pertinente. Sendo assim, colocam-me em diálogo com uma matriz francesa de pensamento sobre o tema da paisagem (Sansot 1983, 1989; Corbin 2001; Berque 2000; Roger 1997), entre outros, que neste estudo opero livremente.

É de um conjunto paisageiro atravessado por formas biosociais que trato aqui e do qual a pesca cooperativa é uma fulguração sensivel que expressa a cosmopolítica de ontologias entrelaçadas no estuário, situadas na heterogeneidade sociocultural urbana em tensão. Quanto às figurações de eventos interacionais entre humanos, cetáceos e peixes a partir de seus mundos-próprios em relação é preciso atentar para os seus frames dinâmicos e proxêmicos envolvendo jogos e predação, convivialidade, dicas e sinais, vocalizações, movimentos mais ou menos abruptos; a fluidez de imagens confundindo consciente e inconsciente; as águas salobras e suas complexidades mestiças, suas convergências de meios e inteligências que indicam ser a pesca cooperativa um fenômeno zooantropológico extremamente complexo no mundo urbano contemporâneo.

Sendo assim, o fenômeno biossocial como um encontro mais ou menos tensional de experiências culturais na barra - já que o coletivo Tursiops que maneja a ambiência junto aos humanos coloca em ação suas práticas e entendimentos do seu lugar de pertença, mediante os horizontes de seus mundos-próprios, põe em movimento o fluxo de coisas e sentidos nas complexas relações (que ligam em separado os existentes) através de suas coderivas ${ }^{28}$ no/pelo estuário do Tramandaí, nas linhas que desenham movimentos na água e que encontram o trançado das tarrafas, a profusão de malhas que se atravessam e (re) desenham linhas nos horizontes de relações, para evocar imagens ingoldianas (2007), mas também de certas redes de significados (à la Geertz 2008) que aproximam personas humanas e não-humanas, animando a simbólica das intencionalidades das interações humanimais, como é o caso do enlace tensional da pesca cooperativa no contexto urbano. 
É preciso considerar as associações como formas de socialidade que assumem feições de jogo, bem como as táticas utilizadas pelos coletivos como um conjunto de 'técnicas corporais' (Mauss 1974) e formas de servir-se tanto dos seus corpos quanto das ferramentas/ artefatos (tarrafas) nas interagências de cercamento e ataque, além da não linearidade das agências do tipo captura-fuga que ocorre na predação, um evento performático de sociação altamente ritualizado. Como dito antes, os peixes precisam lidar com as técnicas de pesca cooperativas como jogo social conflitivo, agonístico e que implica evitamento e fuga em relação a ambos os predadores.

O interessante, neste caso, é buscar compreender alguns aspectos do fenômeno que possibilitem aderir à perspectiva dos pescadores (e de pessoas próximas a eles) sobre as suas interações com os botos na barra, relacionados aos processos comunicacionais entre cetáceos e humanos, que ao mobilizarem certos padrões ${ }^{29}$ e se associarem entre si inteligente e habilmente produzem sociações interespécies complexas em diferentes momentos do ano. A questão é como essas imagens duram no tempo sob a forma sensível de experiências compartilhadas em torno do que chamaria aqui de paisagens coexistenciais pluridiversas (inter ou multiespécies), ideia ligada à perspectiva durandiana (1989) das imagens, de seus fluxos e convergências, e que entendo como expressões do imaginário: suas possibilidades comunicacionais interespécies, sensíveis, porque ontológicas, aproximam horizontes tais elementos contribuem para nuançar a minha visada sobre os fatos etnográficos sócio animais (Baratay 2010).

E nestes termos, tanto as pessoas quanto as espécies de tainhas, bem como os botos quando praticam a barra, constituem um fato etnográfico passível de ser pensado (portanto, de ser 'construído') como sendo do âmbito de uma Antropologia Urbana, evocando uma cidade que traz consigo potenciações ecológicas mais-do-que-humanas, ou tantas outras feições ecológico-epistemológicas que se possa dar à urbe, que aqui tanto tem relação com a antropologia da quanto na cidade. Eu diria que isto tende a uma Ecoantropologia Urbana. 
Tal noção refere-se à tentativa de estabelecer a dialogia entre campos disciplinares e, assim, de aproximar temas como Ecologia e Antropologia Urbanas em consonância com a sociologia simmeliana $(1977 ; 1988)$ e a fenomenologia de Schutz (in Wagner 1979), que se volta às experiências e ao mundo da vida quando se pratica o meio urbano com os outros-não-humanos. Tal reflexão exige, portanto, a ultrapassagem de determinações geo e/ou biológicas, tanto quanto daquelas de caráter simbólico: nem tanto à evolução como sinônimo de exercício vantajoso da seleção natural, ou dos caminhos prédefinidos pela genética, nem a supremacia da representação, do construtivismo que inventa porque é culturalmente singular e se sobrepõe a materialidade sensível dos entes e coisas do/no mundo.

Nestes termos, uma cosmopolíticas que reinsere a ciência num patamar crítico acerca da cisão cultura-natureza/humano-não humano, e a re-situa no horizonte hermenêutico de uma natureculture, onde a indissociabilidade dos entes é simbiótica pela deriva das relações biosociais, bem como ontológica, pelo devir coexistencial de seres e seus pontos de vista no mundo sensível, revela que a fenomenologia de tais interações une carne e senciência (como vibração do multidiverso do espírito nos seres) - assim como, o construto urbano - num formismo intenso que (re)arranja conteúdos e pulsa enquanto fulguração paisageira, ali mesmo onde se pratica o mundo como diferenças coligadas, como tensão política e cotidiana na configuração de assembleias mais-do-que-humanas na urbe.

É preciso encontrar o ponto de inflexão entre carne e símbolo, entre matéria e espírito, ou ainda, entre a alma nas coisas e as coisas que animam a alma, seu hibridismo fértil, e por isso, que não dissocia o ser do mundo - especialmente, no urbano - modernamente entendido como um observador de panoramas, nem reifica o fora de si como oposição a interioridade do ser, e vice-versa. A sinergia entre tais dimensões, de suas potências imaginárias dadas na recursividade criadora entre dentro e fora reaproximam a ecologia e a simbólica, e constituem a aura das paisagens onde o humano figura como um 
dos dínamos da integração entre o sensível e a significação (como coloca Sansot 1983) e, assim, fulgura como paisagem no mundo, e não apenas a observa como uma externalidade.

Tal ultrapassagem, como dito antes, requer um questionamento dos limites entre o que se pensa como dentro ou fora do ser (humano) no mundo - e neste sentido ele não age apenas nesse mundo porque ele é, em si mesmo, uma das feições da agência do mundo fenomênico - ele afeta e é afetado, e isto produz formas entrelaçadas, e conteúdos conexos com os 'Outros' (humanos, não humanos e sobre-humanos) porque implica uma posição agentiva no meio, no seu fluxo, pois a afecção seria justo o deixar-se ir no mundo em que habito e transformo na medida em que ele me reconfigura na própria tendência de durar no descontínuo. A cidade é, num sentido contraditorial, uma reverberação das afecções dos entes no devir das paisagens: sua reconfiguração constante nas cidades brasileiras é um jogo complexo entre lembranças e esquecimentos, a produção de formismos que se desdobram no espaço e no tempo.

Há um dinamismo sensível na cidade, uma proliferação de associações que geram laços, afecções que configuram uma Ecoantropologia Urbana: uma paisagem por si só é fluxo de interagências de existentes co-construindo simbólica e ecologicamente seu mundo compartilhado, conformando-o, encompassando/ entrelaçando diferenças em unidades autopoiéticas que se transformam e recompõem - enfim, que se transcriam - obviamente, se respeitado o seu direito de ser no mundo. A paisagem seria um sujeito de direito (e não se deve querer apenas o antropocêntrico direito à paisagem). Portanto, ao se desdobrar em fluxos de agências ela redefine constantemente tanto os conteúdos como as formas em devir no espaço e no tempo de um lugar praticado, porque há movência no seu derivar criativo, nas suas assembléias híbridas. As paisagens são ontologias possíveis que acolhem ontologias outras em si mesmas, elas participam ativamente de uma cosmopolítica, colocam culturas em tensão. 
As reflexões que suscitam abordagens como essas, por outro lado, ensejam o reposicionamento de pontos de vista no tratamento heurístico do lugar de pertença dos não humanos vivos na urbe, na medida em que existentes Outros coproduzem nichos com os humanos para além da mera sinantropia. Ou melhor, se consideramos a sua presença mais ou menos tensional no domus é preciso vislumbrar não apenas as potenciais possibilidades de associações conosco comensalismo, inquilinismo, parasitismo e outros 'ismos' - a fim de alargarmos a mútua coexistência e repensarmos a simbiose simbólicoprática que estabelecem conosco, pois coabitamos as paisagens a partir de mundos-próprios (Umwelt), que encerram ecologias, subjetividades, pontos de vista, ontologias que entrelaçam sinergisticamente as diferenças numa unicidade processual, ligando anthropos e oikos nas suas multiplicicidades.

É preciso re-situar as agências não humanas no seio da urbe - e, por isso mesmo, no que se denominou de gestão urbana - especialmente as animais, que são as que me interessam mais neste debate, e tomá-las como um jogo complexo de sociações multiespécies imersas no que alguns têm chamado de sinurbização (Luniak 1999; Francis, Chadwick 2012). Ora, não se trata apenas da obviedade de que no Capitaloceno (Moore 2016), o humano tem invadido/depredado/aniquilado o vivo nas paisagens e as paisagens vivas, por intermédio de avanços civilizatórios que instauraram um novo processo de extinção em massa, que é justo uma faceta da cultura do terror (Taussig 1993), mas de refletir sobre o fato de que neste processo de expansão, mediante temporalidades acidentadas/turbulentas que reconfiguram objetiva e tragicamente os espaços, e as paisagens do Outro (que são os seus territórios de pertença), redefinimos, paradoxalmente, o nosso lugar no mundo - essas são dimensões da tragédia da cultura nos termos simmelianos.

Isto envolve pensar as tensões criativas entre selvagem e doméstico na urbe, nas relações de proximidade-distância entre os existentes, ou melhor, nos lugares praticados pelos humanos onde espécies 
companheiras (Haraway 2010) coexistem em situações de convívio próximo, de domesticidade relativa, de amansamento, ou de selvageria urbanizada, por assim dizer. A presença da natureza/dos naturais na urbe não deve ser entendida apenas como uma construção ou um conjunto de representações, mas, sim, como a concomitância de sua existência palpável e negociável pelo ajustamento tensional de sua presença junto a nós (pois é adaptativo e criativo), de sua materialidade plausível conosco, em nossas interagências paisageiras.

Precisamos refletir sobre as agentividades animais vinculadas às formas adaptativo-evolutivas de ocupação intencional das e nas cidades, dos seus mosaicos urbano-paisagístico-ecológicos que combinam tanto a localidade dos espaços (ambiências) quanto à espacialidade dos lugares citadinos, como feições complexas de co-construções humanimais de nichos existenciais híbridos, mestiços. No meu ponto de vista, para o bem e para o mal, a barra do rio Tramandaí é um dos exemplos mais acabados desse processo em andamento na porção austral brasileira.

A barra do Tramandaí é um superartefato híbrido de humanos e não humanos (águas/dunas/animais/plantas/coisas: pontes, guiacorrente, molhes, edificações do entorno, sistemas de tubulações e cabos elétricos, redes de internet) no mundo urbano contemporâneo - ali a cidade cyborg (Swyngedouw 2001) encontra a artesania da vida vivida, entre os arranha-céus que almejam a estratosfera, as megapontes do delírio desenvolvimentista e o cotidiano praieiro que reúne coletivos multiespécies em socialidades sensíveis, onde modos de vida humanimal, por assim dizer, se associam fortemente como na pesca cooperativa entre os botos-da-barra e pescadores artesanais na captura de tainhas, quando vida e morte se entrelaçam numa dinâmica interespécies, micro-sociológica, acionando o prosaico e o sensível no mundo da vida, acomodando e tensionando experiências em relação nas paisagens estuarino-lagunares, numa ecologia complexa que liga humanos e não humanos e faz das paisagens uma experiência conjunta mais-do-que-humana. 
No caso da pesca cooperativa não se trata do multiespecífico apenas, porque isso seria reduzir o sinergismo das formas que emergem nas assembleias/associações/círculos de agregação possíveis naquele contexto de significações biossociais interespécies. A barra é justo uma zona de contato, e encerra um espaço-tempo onde as memórias coletivas se assentam de maneira intensa, diversas e correlatas no lugar, porque como nos lembra Rupert Sheldrake (2009), tanto humanos quanto não humanos detêm memórias coletivas de suas espécies que, nos termos de Maturana (1990) estariam em congruência com o meio, seus lugares praticados (Certeau 1994). A dinâmica das imagens mobilizadas em nossa memória é distinta e particularizada de acordo com os coletivos de que participamos, e possui complexidades outras, mas nem por isso está ausente, a sua maneira, no mundo-próprio dos botos da barra, por exemplo. As paisagens como experiências sensíveis na duração revelam a associação complexa de memórias de entes distintos, que dinamizam o seu devir formal no espaço e no tempo de suas (co)existências, e isso leva a desdobramentos ecológicos e simbólicos de variância extrema.

A barra do Tramandaí confunde urbano e rural, cidade e natureza, e mostra que os limites entre eles são tênues, uma vez que pescadores artesanais e espécies ameaçadas de extinção convivem com processos de urbanização acelerados que transformam as suas paisagens intensamente pelo menos desde os anos 1960, mas certamente desde 1937, com a abertura da barra pelos pescadores. Ela é, assim, um lugar de conflitos socioambientais, um conjunto de paisagens de tensão ecocultural com forte caráter (geo)político porque define fronteiras municipais. Além disso, a barra revela-se um patrimônio biocultural e expressão do pensamento paisageiro dos coletivos humanos em consonância com a ecologia litorânea/estuarino-lagunar.

O problema das ambiguidades em torno do termo paisagem reside no fato de que ele está associado a oposições binárias que deveriam ser pensadas, estruturalmente, como complementares, mas são, não raro, pensadas como excludentes, o que é um erro grave porque separa 
cultura/natureza, dentro/fora do ser. Penso as paisagens como formas em devir e, por isso, transformacionais, daí que elas são sempre loci de tensão entre esquecimentos e lembranças, entre finitude e perdurância em lugares praticados na duração de uma natureculture onde somos a paisagem com os Outros.

Nestes termos, a barra apresenta-se como um corredor de mediância (médiance) que instaura complexas formas de trajeção de convergências ecológico-simbólicas mobilizadoras de paisagens coexistenciais interespécies que duram no tempo, e se transformam de acordo com os arranjos multiespécies, mas sempre modeladas por desígnios 'desenvolvimentistas' humanos. Há, assim, redes de significados entrelaçadas a teias ecológicas, onde pescadores, turistas, pesquisadores, moradores convivem com coletivos animais diversos, figurando agentivamente nas paisagens e fulgurando ('a aura da paisagem'), contextualmente, a partir de trajeções paisageiras, que são justo o caráter híbrido de sua potência ecológico-simbólica, como devir processual que fornece a fisionomia do lugar na sua historicidade.

Numa paisagem há tanto a função do real quanto do irreal, do visível e do invisível na sua trajeção. Ela é, portanto, um fenômeno do imaginário, de sua materialidade sensível, por assim dizer. $\mathrm{O}$ meio, desta forma, é um processo e não uma mera parte do contexto físico. É por intermédio dele que se faz o mundo em ato - a trajeção em Berque (2000) é uma noção herdeira do pensamento durandiano, do trajeto antropológico que ao evocar um processo de assimilaçãoacomodadora coloca a persona como agente subjetivo em consonância com as demandas objetivas onde se insere. $\mathrm{O}$ mundo se constitui nesse jogo subjetivo-objetivo de evocação/(re)elaboração de imagens. Ora, se isto está certo para o humano, é análogo (talvez homólogo) aos animais, pelo menos a alguns deles - principalmente se os tomarmos como pessoas não humanas, o que se complexifica ainda mais com os cetáceos pela constituição de seus mundos-próprios (Umwelt), uma vez que devemos considerá-los como sujeitos no mundo com agentividade senciente produtora de nichos existenciais, detentores de 
expressões culturais outras, de 'tradições' como querem os biólogos. A questão é que para o humano tais dimensões levam a complexidades socioculturais distintas em relação àquelas referidas aos animais, mas não necessariamente superiores ou melhores, apenas diversas.

Por fim, uma Ecoantropologia Urbana, como proponho, necessitaria o repensar dos rumos urbanos. A cidade deveria ser, então, o resultado de escolhas humanas e uma possibilidade renovada de existência com as diferenças, quiçá uma utopia realizável de ontologias em profusão no devir de paisagens, antes de constituir-se na figuração antropocêntrica da negação de tudo o que não é espelho, as feições do demens ${ }^{30}$.

\section{Notas:}

1 Agradeço a Cornelia Eckert e Ana Rocha (e a equipe do NAVISUAL/BIEV/ UFRGS), supervisoras do projeto de pós-doutorado sênior realizado na UFRGS, bem como o convívio com os estudantes que participaram da Oficina Passos para uma Ecoantropologia Urbana que ministrei no segundo semestre de 2018; aos colegas da UFRGS - Litoral Norte: Olavo Marques e Marlise Dal Forno (CLN), e Ignácio Moreno (e membros do Projeto Botos da Barra), no CECLIMAR; à colega Andréa Osório (UFF) pelo apoio de sempre e pela leitura atenta e crítica. Ressalto que os possíveis erros neste ensaio são todos meus. Agradeço a bolsa de pós-doutorado concedida pelo $\mathrm{CNPq}$.

2 À experiência de campo somo a leitura de diversos autores que constam nas referências bibliográficas, alguns deles são citados diretamente no ensaio enquanto outros foram incorporados, porque 'antropofagizados', livremente no processo criativo que se desdobra nas reflexões que proponho. Sou devedor dos insights de todos eles. Além disso, me alio à proposta crítica de Kohn (2015) sobre o que entende por uma antropologia ontológica - que compreendo como sendo politicamente situada, poeticamente engajada em termos ético-estéticos e passível de entrelaçar sensível/ tensionalmente mundos mediante uma ecosofia das relações multidiversas (maisdo-que-humanas), jamais redutíveis umas as outras porque produtoras de diferenças coligadas em devir, o que seria o mesmo que dizer de paisagens. Por último, entendo que uma antropologia ontológica é devedora criticamente de uma matriz disciplinar (Cardoso de Oliveira, 1987) cara ao pensamento antropológico.

3 O gênero Tursiops é comumente associado a figura emblemática de Flipper, personagem animal de uma série de televisão norte-americana muito famosa nos anos 60. Neste caso, trata-se de Tursiops truncatus, que no contexto gaúcho, ocorre em simpatria com Tursiops gephyreus em áreas costeiras, sendo que o primeiro tende a ocorrer em zonas mais distantes da costa, conhecido na região como Caldeirão. 
4 Há significativa produção sobre o tema da cosmopolítica como desdobramentos da proposta de Isabelle Stengers, aqui me baseio principalmente em Stengers (2007), Latour (2018), Blaser (2018).

5 Aqui aproximo livremente o pensamento de Stengers (2005) ao de Certeau (1997).

6 Sigo o preceito durandiano (1989) da unicidade - como dinâmica processual de relações e formas e, portanto, de imagens em devir, e não o da unidade como forma estática.

7 Ver a obra organizada por Jason Moore (2016), bem como os seus trabalhos (2013a, 2013b), além de Haraway (2015) e Haraway et al. (2015).

8 Não tenho espaço aqui para debater sobre a significativa produção acerca do tema da tradição entre coletivos de cetáceos, e de como os biólogos contemporâneos associam o referido tema à noção de cultura entre essas sociedades animais com singularidades intra-espécies, mas também interespécies. Em momento oportuno pretendo contribuir com o debate em questão. Para tanto ver Simões-Lopes; DauraJorge; Cantor (2016), Gallef Jr (1992), Laland \& Gallef (2009), ou as considerações de Lestel (2003) sobre culturas animais.

9 No contexto paraense as minhas observações iniciais de campo na cidade de Mocajuba, junto ao Mercado público da cidade, localizado às margens do Tocantins indicam as interações de pessoas com botos-do-Araguaia (Inia araguaiaensis). As pesquisas de longa data de Rodrigues et al (2019) naquele contexto são extremamente importantes. Os autores indicam associações interespecíficas entre humanos e 'botos-rosas' (Inia geoffrensis) junto ao mercado da cidade de Santarém, situado às margens do Tapajós.

10 Informações obtidas a partir das observações do pesquisador Ignácio Moreno. Em diferentes momentos deste artigo farei referência às informações que obtive ao longo do trabalho de campo mediante diálogos que travei com os pesquisadores, quando recebi o apoio de toda a equipe do Projeto Botos da Barra para a realização da etnografia.

11 Parte deste ensaio tem relação direta com os estudos sobre memória. Neste caso, ressalto o debate que construo com o colega Olavo Ramalho Marques (ver o seu artigo de 2017 e o belo documentário dirigido pelo antropólogo, intitulado A Pesca do Boto), mais especificamente, sobre as memórias relativas à pesca cooperativa nas paisagens do Tramandaí.

12 A ideia de algo figurar como um vetor de relação segue a abordagem de uma sociologia sensível, como é a de Michel Maffesoli (1987).

13 A questão da comunicação entre cetáceos é muito complexa e merece um artigo sobre o tema, no momento faço referência aos estudos importantes de Bateson (2000), Lilly (1978), Laland \& Gallef (2009).

14 Óbvia menção à ideia de educação da atenção de Ingold (2010).

15 E que não seria tão distinto dos meninos que se iniciam na pesca cooperativa com tarrafas, pois necessitam observar as dinâmicas do estuário e dos botos a fim de estabelecerem as suas próprias hermenêuticas das paisagens, ao mesmo tempo em que são estimulados pelos pescadores mais experientes, obtendo dicas de como procederem e desenvolverem suas habilidades na prática. 
16 Aqui me limito a informar que a prática de pesca cooperativa no estuário do Tramandaí é mantida de forma diversa daquele que ocorre em Laguna (SC), para o caso deste último ver Catão (2019).

17 Ver o trabalho de conclusão de curso em Biologia (UFRGS), de Silva (2019).

18 Apesar disso, os pescadores têm consciência do papel desempenhado pelos coletivos Tursiops que cooperam na captura dos peixes, e afirmam frequentemente que os 'botinhos' são importantes para o ganha-pão diário, enfim, para a manutenção da economia familiar, já que os animais abatidos, não raro, são eviscerados e comercializados na barra mesmo, sendo o restante levado para o consumo doméstico. Portanto, a associação o é fundamental para a continuidade dos modos de vida dos pescadores artesanais de tarrafa no estuário do rio Tramandaí

19 Em termos bachelardianos (1988) a fenomenologia das paisagens da barra mescla a matéria móvel das águas àquela da praia na sua dinâmica transformacional, à deposição constante de areias pelo vento; os microrganismos que nutrem os cardumes às macrofilas que são arrastadas pelas marés, ou à macrofauna que interage no estuário, como as aves aquáticas - limícolas, dulciaquícolas, marinhas, algumas delas em perigo de desaparecerem; bagres e lontras ameaçados de extinção; lobos-marinhos, tartarugas-marinhas e outras espécies, que constituem as formas vivas ou não, que coadjuvam no jogo 'pesca cooperativa' pela sua interação sistêmica e processual nas paisagens, e de certa forma com o triângulo em relação em suas explosões de eventos e contatos, uma vez que produzem em separado (suas dimensões ônticas e ontogênicas, como indivíduos e populações em relação ecológica) as conexões possíveis no contexto barra, conformando um conjunto heterogêneo de paisagens em devir numa zona de contato ecocultural, configurando uma poiesis criativa.

20 Não cabe por ora entrar no rico debate sobre as complexas relações entre Antropologia e Etnografia para os estudos do mundo urbano contemporâneo das cidades brasileiras; teoria e método enquanto processos co-participes do métier e do ofício do antropólogo, como aparecem nas questões evocadas pelas reflexões de Mariza Peirano (2014), Tim Ingold (2011), Viveiros de Castro (2002b), ou das complexidades do 'antropólogo na figura do narrador' (Rocha \& Eckert 2005), mas também àquelas já clássicas colocadas por figuras como Gilberto Velho $(1987,1994)$ e Roberto DaMatta (1978), entre outros autores, mas apenas de referencia-las como centrais neste ensaio.

21 Longe de mim reduzir uma a outra, mas é preciso considerar que tanto os saberes disciplinares e suas construções no campo da Antropologia são relevantes para a compreensão do fenômeno estudado, quanto a referência ao lugar que as ontologias ocupam na antropologia contemporânea a partir da virada que ela experimenta (ver Viveiros de Castro 2002a; Kohn 2015; Santos \& Tola 2016, entre outros) na direção do pluriverso, ao extra-humano, ou o que quer que seja, no sentido de ir além do humano sem negá-lo.

22 Abordar um fenômeno interespécies sui generis com implicações ecossistêmicas e multiespécies incomuns no meio urbano, considerando a sua raridade no ecúmeno exige de parte do antropólogo não apenas a visita às diferentes matrizes de pensamento disciplinar, como evocam as 'viradas' (turns) no pensamento conceitual que complexificam e tensionam as relações entre antropologia e etnografia, pelo 
menos desde a segunda metade do século XX, ao lugar que os animais ocupam nos estudos etnográficos contemporâneos. É preciso, ainda, realizar certas incursões ao campo teórico do que chamarei aqui de uma antropologia simbólica - que iria desde a crítica batesoniana ao funcionalismo de Malinowski, ou ao estrutural-funcionalismo radcliffe-browniano, passando pelo estruturalismo de Lévi-Strauss - a evocação de uma ciência do concreto - e as suas conexões com a antropologia da natureza (Descola 2001), ou com o perspectivismo (Viveiros de Castro 2002a), por exemplo, pela via do multinaturalismo, que no caso da pesca cooperativa se chocaria com a noção de pesca como natureza expropriável e mobilizada pela obtenção de recursos, própria a uma lógica do Capitaloceno (Moore 2016) ou a possibilidade, à Latour, de modos de existência configuradores de ecologias plurais na conformação crítica de um mundo comum não-modernizante, por assim dizer

23 Aqui tanto uma matriz batesoniana que se expande a partir de sua visão ampla da ecologia ( Bateson 1986, 2000), quanto uma leitura de Félix Guattari (1990) que recupera o pensamento do autor são inspiradoras, assim como os usos mais recentes do termo, no âmbito do pensamento de Maffesoli (2017), fazem eco em minhas considerações.

24 Me restrinjo aos cetáceos porque incluir os peixes neste artigo me levaria a caminhos mais complexos, necessitando de reflexões mais pausadas.

25 Utilizo a expressão em espanhol operacionalizada por mim como um sinônimo de 'fabricação' das imagens, talvez de agenciamentos sensíveis porque processuais de imagens em devir, ou ainda, próximo ao sentido de formismo, neologismo utilizado por Maffesoli (1983) inspirado em Simmel.

26 Estas ideias que evoco estão presentes de forma muito evidente no clássico de Edgard Morin (1975), mas se aproximam da noção de symbiogenesis de Haraway (2016), que ecoa naquelas de Lovelock e Margulis (Sahtouris 1997), ou na ideia de paisagem que tem uma longa linhagem, para tanto ver o meu texto (Silveira 2009), mas que neste ensaio tocam as perspectivas de Ingold (2000), ou de Tsing (2018), por exemplo.

27 Utilizo a noção de epifania no sentido que Eliade (1992) fornece ao termo, enfim, enquanto explosão fenomênica de um evento, como fulguração vertiginosa da imagem sagrada, neste caso, transfigurada à mundanidade: a pesca cooperativa seria um evento mais ou menos explosivo, oscilando entre técnica e maestria pacienciosa na perseguição da presa, e eventos dinâmicos de exercício de força e presteza na sua captura, que constituem a cena ou quadro de imagens memoriais que duram no tempo, na medida em que emergem e se reconfiguram no devir das paisagens estuarinas.

28 Aqui utilizo a expressão no sentido que Humberto Maturana (1978; 1992) opera com o termo - de derivar juntos - ou seja, na díade botos-humanos há derivas ontogênicas que se coadunam àquelas de ordem ontológicas, e isto para mim, é uma fulguração cosmopolítica enquanto um fato de vida compartilhada na polis, nas vicissitudes do mundo urbano com suas contradições e promessas de bem-estar, enfim, onde naturecultures manifestam suas vibrações sensíveis como paisagens coexistências em devir.

29 Esses padrões a que me refiro são até certo ponto repetitivos, mas paradoxalmente mostram-se sempre abertos às vicissitudes dos acontecimentos e, por isso, 
imprevisíveis, não-lineares, pois desdobram-se no jogo performático da pesca cooperativa sempre mediados pelas movimentações mais ou menos sazonais das espécies de tainhas (mas, também de outros peixes) no estuário ao longo do ano.

30 A ideia de Homo demens é tributária do pensamento de Morin (1975), de suas reflexões acerca do mundo no qual participamos/co-produzimos com os outros seres, mas que ao mesmo tempo destruímos. Participamos do vivo na medida em que o negamos e colocamos em risco a própria vida do planeta.

\section{Referências:}

ARAÚJO IINO, Fátima. 2017. Pescadores artesanais na Praia da Tesoura, Laguna/SC: Reflexões sobre sociabilidades e apropriações do espaço. Dissertação de Mestrado. Florianópolis: UFSC.

BACHELARD, Gaston.1988. A Poética do Espaço. São Paulo: Martins Fontes.

BARATAY, Éric. 2010. "Le sócio-anthropo-logues et les animaux. Réflexions d'un historien pour um raprprochement des sciences”. Societés, 108:9-18.

BATESON, Gregory. 2000. Steps to an ecology of mind. Chicago: University of Chicago Press. Alves.

1986. Mente e Natureza. A Unidade Necessária. Rio de Janeiro: Francisco

BERQUE, Augustin. 2000. Médiance de milieux en paysage. Paris: Éditions Belin.

BLANC, Nathalie. 2004. "De l'écologique dans la ville". Ethnologie Française, 4(34):601-607.

BLASER, Mario. 2018. “Uma outra cosmopolítica é possível?”. R@U, 10(2):14-42.

BUSNEL, René-Guy. 1973. "Symbiotic relationship between man and dolphins. Transactions". New York Ac. of Sciences, 2(35):112-131.

CAILLOIS, Roger. 2014. Les jeux et les homes. Paris: Gallimard.

CALABRESE, Omar. 1989. A idade neobarroca. Lisboa: Edições 70.

CARDOSO de OLIVEIRA, Roberto. 1987. "A Categoria de (Des)Ordem e a PósModernidade na Antropologia”. Anuário Antropológico, 11(1):57-73.

CATÃO, Brisa. 2019. Impressões na água: peixes, botos e pescadores na pesca conjunta em Laguna. Tese de Doutorado. Belo Horizonte: UFMG.

CERTEAU, Michel de. 1997. A Invenção do Cotidiano. Artes de fazer. Rio de Janeiro: Vozes.

CORBIN, Alain. 2001. L'homme dans le paysage. Paris: Textuel.

DAMATTA, Roberto. 1978. "O ofício de Etnólogo, ou como ter Anthropological Blues”. Boletim do Museu Nacional, 27:1-15. 
DESCOLA, Philippe. 1994. In the society of nature. A native ecology in Amazonia. Cambridge: Cambridge University Press. 2001. Anthropologie de la nature. Leçon inaugurale. Collège de France (www.college-de-france.fr.; acesso em 15/10/2008).

DESCOLA, P. \& PÁlSON, G. (eds.). 2001. Naturaleza y sociedad. Perspectivas antropológicas. México: Siglo Veintiuno.

DOOREN, T. van. \& ROSE, D. B. 2012. "Storied-places in a multispecies city". Humanimalia: a journal of human/animal interface studies, 2(3):1-27.

DROZ, Y. \& MIÉVILLE-OTT, V. (eds.). 2005. La polyphonie du paysage. Lausanne: Presses Polytechniques et Universitaires Romandes.

DURAND, Gilberd. 1989. As Estruturas Antropológicas do Imaginário. Lisboa, Presença. 59-74.

ECKERT, Cornelia. 2009. "As variações 'paisageiras' na cidade e os jogos da memória”. In SILVEIRA, F. \& CANCELA, D. (ed.): Paisagem e Cultura: dinâmicas do patrimônio e da memória na atualidade, pp 87-100. Belém: EdUFPA.

ELIADE, Mircea. 1992. O Mito do Eterno Retorno. São Paulo: Mercuryo.

ELIAS, Norbert. 1992. A busca da excitação. DIFEL: Lisboa.

ESCOBAR, Arturo. 2013. "En el trasfondo de nuestra cultura: la tradición racionalista y el problema del dualismo ontológico”. Tabula Rasa, 18:15-42.

FAVRET-SAADA, Jeanne. 2005. "Ser afetado". Cadernos de Campo, 13(13):155-161.

FRANCIS, R. A., LORIMER, J. \& RACO, M. 2011. "Urban ecosystems as 'natural' home for biogeographical boundary crossings". Trans. Ins. Br. Geogr., 37(2): 183-190

FRANCIS, R. A. \& CHADWICK, M. A. 2012. "What makes a species synurbic?". Applied Geography, 32:514-521.

FUENTES, Agustin. 2010. "Naturalcultural encounters in Bali: monkeys, temples, tourists, and ethnoprimatology”. Cultural Anthropology, 25(4):600-624.

GALLEF Jr, Bennet. G. 1992. "The question of animal culture". Human nature, 3(2): $157-178$.

GEERTZ, Clifford. 2008. A interpretação das culturas. Rio de Janeiro: LTC.

GOODBUN, Jon. 2011. "Gregory Bateson, Critical Cybernetics and Ecological Aesthetics of Dwelling". Field Journal, 4(1):35-46.

GOUABAULT, Emmanuel. 2010. "Pour une mythanalyse des relations anthropozoologiques. L'étude du phénomène dauphin”. Sociétés, 108(2):59-73.

GUATTARI, Félix. 1990. As três ecologias. Campinas, Papirus.

HALBWACHS, Maurice. 2006. A memória coletiva. São Paulo: Centauro. HALL, Edward T. 1977. A dimensão oculta. Rio de Janeiro: Francisco Alves. 
HARAWAY, Donna. 2010. Manifeste des espèces de compagnie. Chiens, humains et autres partenaires. Paris: Éditions de l'éclat.

2015. "Antropocene, Capitalocene, Plantationocene, and Chthulucene: making kin". Environmental Humanities, 6:159-165.

2016. Staying with the trouble. Making kin in the Chthulucene. Duhram and London: Duke University Press.

HARAWAY, D. et al. 2015. "Anthropologists Are Talking - About the Anthropocene". Ethnos, 81(3)1-30.

HIRSCH, E. \& O'HANLON, M (eds.). 1995. The anthropology of landscape. Perspectives on place and space. Oxford: Clarendon Press.

HUIZINGA, Johan. 1996. Homo ludens. O jogo como elemento da cultura. São Paulo: Perspectiva.

ILHA, Elisa B. 2016. Pescadores e botos: histórias de uma conexão em rede. Trabalho de Conclusão de Curso. Porto Alegre: UFRGS.

INGOLD, Tim. 2000. The Perception of the environement. Essays livelihood, dwelling and skill. Londres: Routledge. . 2007. Lines. A brief history. London and New York: Routledge. 2010. "Da transmissão de representações à educação da atenção". Educação, 1(33):6-25.

. 2011. "Anthropology is not Ethnography." In INGOLD, T. (ed.): Being Alive, pp. 229-243. Routledge: London and New York.

INGOLD, T. \& PALSSON, G. (eds.). 2013. Biosocial Becomings. New York: Cambridge University Press.

KIRKSEY, S. E. \& HELMREICH, S. 2010. "The emergence of multispecies ethnography". Cultural Anthropology, 4(25):545-576.

KOHN, Eduardo. 2015. "Anthropology of Ontologies". Annual Review of Anthropology, 44:311-27.

KUCZAJ, S. A. \& ESKELINEN, H. 2014. "Why do Dolphins Play?". Animal Behavior and Cognition, 1(2):113-127.

LALAND, K. N. \& GALLEF, B. G. (eds.). 2009. The question of animal culture. Cambridge/London: Harvard University Press.

LATOUR, Bruno. 1994. Jamais fomos modernos. Rio de Janeiro: Ed. 34. .2008. Reensamblar lo social. Una introducción a la teoria Del actor-red. Buenos Aires: Manantial.

2018. "Qual cosmos, quais cosmopolíticas? Comentário sobre as propostas de paz de Ulrich Beck". Revista do Instituto de Estudos Brasileiros, $68: 428-441$.

LESTEL, Dominique. 2003. Les origines animales de la culture. Paris: Flammarion. LÉVI-STRAUSS, Claude. 1989. O Pensamento Selvagem. São Paulo: Papirus.

LEVINE, Donald N. (ed.). 1971. Georg Simmel. On individuality and Social Forms. Chicago and London: The University of Chicago Press. 
LEZAMA LIMA, José. 1981. El reino de la imagen. Caracas: Biblioteca Ayacucho. . 1988. A expressão americana. São Paulo: Brasiliense.

LUNIAK, Maciej. 1999. Synurbization-adaptation of animal wildlife to urban development. Trabalho apresentado no " 4 th International Symposium on Urban Wildlife Conservation”, Tucson-Arizona (EUA).

LUPASCO, Stéphane. 1947. Logique et contradiction. Paris: Presses Univesritaires de France.

MAFFESOLI, Michel. 1980. "L'homme contradictoriel". In MAFFESOLI, M. (ed.): La galaxie de l'imaginaire. Dérive autour de l'ouvre de Gilbert Durand, pp. 37-47.Paris: Berg International Eds.

1987. O Tempo das Tribos - O Declínio do individualismo nas Sociedades de Massa. Rio de Janeiro: Forense-Universitária. Cerf.

2017. Écosophie. Une écologie pour notre temp. Paris: Les Éditions du

MALDONADO, Simone C. (ed.). 2011. Georg Simmel: sentidos, segredos. Curitiba: Appris.

MARQUES, Olavo R. 2017. A barra do rio Tramandaí a partir dos olhos dos pescadores artesanais. Trabalho apresentado na "XII Reunión de Antropología del Mercosur", Posadas, Misiones.

MATURANA, Humberto. 1978. "Estratégias Cognitivas". In: MORIN, E. \& PIATELLI-PALMARINI, M. (eds.): A Unidade do Homem: invariantes biológicos e universais culturais, pp 148-172. São Paulo: Cultrix/EdUSP. 1992. "Conhecer o conhecer". Ciência Hoje, 14(84):44-49.

MAUSS, Marcel. 1974. Sociologia e Antropologia. São Paulo: EPU.

MOORE, Jason W. (ed.). 2016. Anthropocene or Capitalocene? Nature, History, and the Crisis of Capitalism. Oakland: Kairos Books.

MORAES FILHO, Evaristo (ed.). 1983. Simmel. São Paulo: Ática.

MORIN, Edgar. 1975. O enigma do homem. Para uma Nova Antropologia. Rio de Janeiro: Zahar Editores.

PEIRANO, Mariza. 1995. A favor da etnografia. Rio de Janeiro: Relume-Dumará. 391.

2014. "Etnografia não é método". Horizontes Antropológicos, 42(20):377.

PÉTONNET, Collette. 1982. "L'Observation flottante. L'exemple d'un cimetière parisien”. L'Homme, 22(4):37-47.

ROCHA, A. L. \& ECKERT, C. (eds.). 2005. O tempo e a cidade. Porto Alegre: EdUFRGS. . 2013. Etnografia da duração. Porto Alegre: Marcavisual.

RODRIGUES, A. L. F. et al. 2019. "Interactions between children, teenagers and botos (Inia araguaiaensis and Inia geoffrensis) in markets and fairs of Eastern Amazon". Ocean and Coastal Management, 172:137-145.

ROGER, Alain. 1997. Court traité du paysage. Paris: Gallimard. 
SAHTOURIS, Elisabeth. 1991. Do Caos ao Cosmos. Interação: São Paulo.

SANSOT, Pierre. 1979. Les formes sensibles de la vie sociale. Paris, PUF.

SANSOT, Pierre 1981. "Le sociologue et le 'retour' du sensible”. L'Homme et la Société, (59-62):223-233.

. 1983. Variations paysagères. Paris: Klincksieck.

. 1996. Poétique de la ville. Paris: Petite bibliotèque Payot.

SANTOS, A. \& TOLA, F. 2016. “¿Ontologías como modelo, método o política? Debates contemporáneos en antropologia”. Avá. Revista de Antropología, 29:71-98.

SCHAMA, Simon. 1996. Paisagem e Memória. São Paulo: Companhia das Letras.

SHELDRAKE, Rupert. 2009. Morphic resonance. The nature of formative causation. Vermont and Toronto: Park Street Press.

SILVA, Helio. 2009. "A situação etnográfica: andar e ver”. Horizontes Antropológicos, 32(15):171-188.

SILVA. Emanuelly. 2019. 'A gente acostuma os olhos': como os pescadores artesanais de tarrafa reconhecem os botos da Barra e percebem as paisagens no estuário do Rio Tramandai. Trabalho de Conclusão de Curso. Porto Alegre: UFRGS.

SILVEIRA, Flávio. 2009. "A paisagem como fenômeno complexo, reflexões sobre um tema interdisciplinar”. In SILVEIRA, F. \& CANCELA, C. (eds.): Paisagem e cultura: dinâmica do patrimônio e da memória na atualidade, pp. 71-83. Belém: EDUFPA.

SIMÕES-LOPES, P. C., DAURA-JORGE, F. G. \& CANTOR, M. (eds.). 2016. "Clues of cultural transmission in cooperative foraging between artisanal fishermen and bottlenose dolphins, Tursiops truncatus (Cetacea: Delphinidae)". Zoologia, 33(6):1-4.

SIMMEL, Georg. 1977. Sociologia. Estudios sobre las formas de socialización. Madrid: Revista de Ocidente.

1988. La tragédie de la culture. Paris: Editions Rivage.

SMUTS, Barbara. 2001. "Encounters with animal minds". Journal of Consciousness Studies, 8(5-7):293-309.

STENGERS, Isabelle. 2005. "An ecology of practices”. Cultural Studies Review, 1(11):183-196.

. 2007. "La proposition cosmopolitique". In LOLIVE, J. \& SOUBEYRAN, O. (eds.): L'emergence des cosmopolitiques, pp. 45-68. Paris: La Découverte.

STRATHERN, Marilyn. 2013. Fora de contexto. As ficções persuasivas da Antropologia. São Paulo: Terceiro Nome.

SWYNGEDOUW, Erik. 2001. "A cidade como um híbrido: natureza, sociedade e “urbanização-cyborg”". In ACSELRAD, H. (ed.): A duração das cidades. Sustentabilidade e risco nas políticas urbanas, pp. 83-104. Rio de Janeiro: DP\&A.

TABAJARA, Luís. 1992. Aspectos da relação pescador-boto-tainha no estuário do rio Tramandaí - RS. In Prefeitura de Tramandaí/UFRGS (eds.): Os botos do Rio Tramandai, pp. 17-49. Canoas: La Salle. 
TAUSSIG, Michael. 1993. Xamanismo, colonialismo e o homem selvagem. Um estudo sobre o terror e a cura. Rio de Janeiro: Paz e Terra.

TSING, Anna L. 2018. "Paisagens arruinadas (e a delicada arte de coletar cogumelos)". Cadernos do Lepaarq, 30(15):366-382.

UEXKULL, Jakob V. 1933. Dos animais e dos homens. Lisboa: Edição Livros do Brasil.

URRY, John. 1992. "The Tourist Gaze and the "Environment". Theory, Culture $\mathcal{E}$ Society, 9:1-26.

VELHO, Otávio (ed.). 1987. O Fenômeno Urbano. Rio de Janeiro: Editora Guanabara.

VELHO, Gilberto. 1987. Projeto e Metamorfose: antropologia das sociedades complexas. Rio de Janeiro: Jorge Zahar Ed. 2011. "Antropologia Urbana: interdisciplinaridade e fronteiras do conhecimento". Mana, 17(1):161-185.

VIVEIROS DE CASTRO, Eduardo. 2002a. A inconstância da alma selvagem. São Paulo: Cosac Naif. . 2002b. "O nativo relativo". Mana, 8(1):113-148.

WAGNER, Helmut (ed.). 1979. Fenomenologias e relações sociais. Rio de Janeiro: Zahar Eds.

WAGNER, Roy. 2010. A invenção da cultura. São Paulo: COSAC NAIFY.

Abstract: The purpose of the article is to discuss the sensitive and cosmopolitical dimensions of cooperative fishing between porpoises and artisanal fishermen in the context of the estuary of Rio Tramandaí (RS), based on a dialogical approach between Anthropology and other disciplines, in order to propose a perspective of studies about the city that I call Urban Ecoanthropology.

Keywords: Dolphins, Fishermen, Estuary, City, Urban ecoanthropology.

Recebido abril de 2020. Aprovado junho de 2020. 